\title{
B-cell leukemia/lymphoma 10 promotes angiogenesis in an experimental corneal neovascularization model
}

\author{
Gaoqin Liu ${ }^{1,2} \cdot$ Peirong Lu $\mathbb{1}^{1,2} \cdot$ Lei Chen ${ }^{1} \cdot$ Wenpeng Zhang ${ }^{1} \cdot$ Mengjiao Wang ${ }^{1} \cdot$ Dan $\mathrm{Li}^{1} \cdot$ Xueguang Zhang ${ }^{2,3}$
}

Received: 19 September 2015 / Revised: 25 November 2017 / Accepted: 9 January 2018 / Published online: 8 March 2018

(c) The Author(s) 2018. This article is published with open access

\begin{abstract}
Purpose Corneal neovascularization (CrNV) arises from many causes including corneal inflammatory, infectious, or traumatic insult, and frequently leads to impaired vision. This study seeks to determine the role of B-cell leukemia/lymphoma 10 (BCL-10) in the development of experimental CrNV.

Methods Corneas from BCL-10 knockout (KO) mice and wild-type (WT) mice were burned by sodium hydroxide (NaOH) to create the $\mathrm{CrNV}$ model and neovascular formation in the corneas was assessed 2 weeks later. Intracorneal macrophage accumulation and the expression of angiogenic factors were quantified by flow cytometric analysis (FCM) and real-time PCR, respectively.

Results The amount of CrNV was determined 2 weeks after alkali burn. Compared to WT mice, the amount of CrNV in BCL-10 KO mice was significantly decreased. FCM revealed that F4/80-positive macrophages were markedly decreased in BCL-10 KO mice compared with WT mice. Reverse transcription PCR showed that the mRNA expression levels of intracorneal vascular endothelial growth factor-A (VEGF-A), basic fibroblast growth factor (bFGF) and monocyte chemotactic protein 1 were reduced in BCL-10 KO mice compared with WT mice.

Conclusion BCL-10 KO mice exhibited reduced alkali-induced CrNV by suppressing intracorneal macrophage infiltration, which subsequently led to decreased VEGF-A and bFGF expression, suggesting that BCL-10 may become a potential clinical intervening target of CrNV.
\end{abstract}

\section{Introduction}

The cornea is a transparent tissue without vessels under physiological conditions and serves as a mechanical barrier and the anterior refractive surface of the eye [1]. Corneal neovascularization $(\mathrm{CrNV})$ is a serious condition that can

Electronic supplementary material The online version of this article (https://doi.org/10.1038/s41433-018-0039-x) contains supplementary material, which is available to authorized users.

$\triangle$ Peirong Lu

lupeirong@suda.edu.cn

1 Department of Ophthalmology, the First Affiliated Hospital of Soochow University, Suzhou, China

2 Jiangsu Key Laboratory of Clinical Immunology, the First Affiliated Hospital of Soochow University, Suzhou, China

3 Jiangsu Key Laboratory of Gastrointestinal Tumor Immunology, the First Affiliated Hospital of Soochow University, Suzhou, China cause a profound decline in vision leading to scar formation, lipid deposition, and immune rejection of corneal grafts [2]. Given the simple structure of the cornea, which lacks appendages (e.g., glands) and pre-existing blood vessels, the accessibility of the tissue, and the availability of a battery of clinical tests that can be adapted in animal models, the cornea has been used as an ideal in vivo model for neovascularization research over 50 years [3]. CrNV occurs when the balance between angiogenic and antiangiogenic factors is tipped toward angiogenic molecules [1]. It represents a major public health concern and is a common pathway to blindness worldwide due to diseases such as trachoma and onchocerciasis, and in the US, $4 \%$ of the population has $\mathrm{CrNV}[4,5]$. Therefore, effective prevention of $\mathrm{CrNV}$ is important in corneal injury to restore vision [6].

B-cell lymphocytic leukemia/lymphoma 10 (BCL-10) is widely expressed in the cytoplasm of normal lymphoid tissues, with the expression level depending on the developmental stage of lymphocytes [7]. For cell activation, BCL-10 can directly bind to the paracaspase Malt1 to assemble signalosomes that control the context-specific 
activation of IKK and NF- $\mathrm{KB}$ and regulate the JNK and p38 MAP kinase pathways [8-12]. A recent report revealed that BCL-10-containing signalosomes can play a critical role in natural killer $(\mathrm{NK})$ cell activation [13]. It was also found that, in BCL-10 KO mice, the absence of BCL-10 leads primarily to a reduction of peripheral NK T-cell numbers [14]. This seems to indicate that BCL-10 has an important role in peripheral NK T-cell persistence. Recently, NK cells have been ascribed functions in cytokine and proangiogenic factor secretion in humans and mice [15-17], such as vascular endothelial growth factor (VEGF), placental growth factor (PIGF), and interleukin-8, and can significantly enhance the growth of transplanted tumors due to their angiogenic activity [18].

It has been reported that BCL-10 plays a critical role in angiogenesis in several types of cancer and other diseases through activation of NK cells [19, 20]. However, the precise mechanisms by which BCL-10 induces inflammatory angiogenesis, especially in the eye, remain unclear. To further address the roles of BCL-10 signaling in experimental CrNV, we used BCL-10 knockout (KO) mice and wild-type (WT) mice to create an experimental $\mathrm{CrNV}$ model using sodium hydroxide $(\mathrm{NaOH})$ and examined the roles of BCL-10 in the processes of angiogenesis in vivo. Inflammatory cells, such as macrophages and neutrophils, infiltrating in the corneas and associated angiogenic factors in CrNV were determined and compared. Herein, we provide definitive evidence of promoting angiogenesis role of BCL-10 in experimental CrNV model. Our data also suggested the potential of BCL-10 targeting therapy to intervene $\mathrm{CrNV}$ in clinical settings and topical application of BCL-10 inhibitor as an adjunctive reagent to reduce NK cell intracorneal infiltration, proangiogenic factor secretion and thereby reduce or prevent $\mathrm{CrNV}$.

\section{Materials and methods}

\section{Reagents and antibodies}

Alexa Fluor 488 donkey anti-rat $\operatorname{IgG}(\mathrm{H}+\mathrm{L})$ and Alexa Fluor 594 goat anti-rabbit $\operatorname{IgG}(\mathrm{H}+\mathrm{L})$ were purchased from Invitrogen Life Technologies (Carlsbad, CA). Rat antimouse CD31 (MEC13.3) monoclonal antibody (mAb), rat anti-mouse-Ly-6G (551495) mAbs, and rat anti-mouse CD49b Abs were purchased from BD PharMingen (San Diego, CA). Goat anti-mouse CD206 (AF2535) polyclonal antibody was obtained from R\&D Systems (Minneapolis, MI). Rat anti-mouse F4/80 (clone A3-1) mAbs was acquired from Serotec (Oxford, UK). Rabbit anti-mouse VEGF-A monoclonal antibody (ab52917) was acquired from Abcam (Cambridge, UK). Rabbit anti-mouse bFGF monoclonal antibody (bs-0217R) and rabbit anti-mouse
NK1.1 (bs-4682R) polyclonal antibody were acquired from Bioss, Inc. (Woburn, MA). FITC-labeled hamster antimouse CD11c Abs (130-102-798) was acquired from Miltenyi Biotec (Bergisch Gladbach, Germany). Goat antiVimentin polyclonal antibody (sc-7558) was acquired from Santa Cruz Biotechnology, Inc. (Santa Cruz, CA). FITCconjugated anti-mouse KRT monoclonal antibody (172085FITC-100 $\mu \mathrm{l})$ and FITC-conjugated rat anti-mouse CD83 (C2435-05E3-100 $\mu \mathrm{g}$ ) monoclonal antibody were purchased from United States Biological (Salem, MA). PE-conjugated swine anti-rat IgG, FITC-conjugated swine anti-rat IgG mAb, FITC-conjugated donkey anti-goat IgG mAb and PEconjugated donkey anti-rabbit $\operatorname{IgG} \mathrm{mAb}$ were purchased from Pierce (Rockford, IL).

\section{Data reporting}

Sample sizes were determined on the basis of similarly conducted studies [21-24]. Mice were randomly assigned into groups matched for sex and age. The investigators were blinded to allocation during experiments and outcome assessment for all the behavioral assays. Each experiment in this study was performed three times.

\section{Animals}

All animal experiments were approved by the Guideline for the Care and Use of Laboratory Animals on the Chinese Medical Academy and the Soochow University Animal Care Committee and were performed in accordance with the ARVO Statement for the Use of Animals in Ophthalmic and Vision Research. Male BCL-10 ${ }^{-/-}$mice backcrossed onto a FVB background and male WT FVB mice weighing 20 to $25 \mathrm{~g}$ were used in this study and were kept in our animal facility under specific pathogen-free conditions. A 12-h day/ 12-h night cycle was maintained during the entire course of the study. Animals were kept in groups of 5 and fed regular lab chow and water ad libitum.

\section{Alkali-induced corneal injury model}

Mice were anesthetized with an i.p. injection of $1.8 \%(\mathrm{v} / \mathrm{v})$ Avertin at a dose of $0.20 \mathrm{ml} / 10 \mathrm{~g}$ body weight. A 2-mm disc of filter paper saturated with $1 \mathrm{~N} \mathrm{NaOH}$ was placed onto the left cornea of each mouse for $40 \mathrm{~s}$, followed by rinsing extensively with $10 \mathrm{ml}$ of PBS. The corneal epithelia were removed using a corneal knife in a rotary motion parallel to the limbus by gently scraping over the corneal surface without injuring the underlying corneal stroma [21]. Erythromycin ophthalmic ointment was instilled immediately following epithelial denudation. At the indicated time intervals (days 0, 2, 4, and 7), mice were killed and the corneas were removed from experimented eyes. These corneas were 
placed immediately into RNALate (Qiagen) and kept at -86 ${ }^{\circ} \mathrm{C}$ until total RNA extraction. In another series of experiments, mice were killed at the indicated time points (days 2 , 4, and 14) after alkali burned and their left eyes were entirely removed from each animal. These eyes were fixed in $4 \%$ paraformaldehyde for immunofluorescence analysis or corneal whole mount fluorescence histochemistry. In some experiments, recombinant mouse BCL-10 or anti-mouse BCL-10 Abs was dissolved in $0.2 \%$ sodium hyaluronate (Sigma-Aldrich) at $10 \mu \mathrm{g} / \mathrm{ml}$. Then $5 \mu \mathrm{l}$ of BCL-10, antimouse BCL-10 Abs preparation or vehicle was applied topically to the alkali burned eye three times per day for 7 days. Each experiment was repeated at least three times.

\section{Biomicroscopic examination}

Eyes were examined under a surgical microsystem (Original magnifications, $25 \times$, Leica MZ16, Wetzlar, Germany) 14 days after alkali injury by two independent observers with no prior knowledge of the experimental procedures, as described previously [21-24].

\section{A double-color immunofluorescence analysis}

A double-color immunofluorescence analysis was performed to detect intracorneal infiltrating NK cells. Briefly, the fixed cryosections ( $8 \mu \mathrm{m}$ thick) were incubated with PBS containing $10 \%$ normal donkey serum and rabbit serum to reduce nonspecific reactions. Thereafter, the sections were incubated with the combinations of rat antiCD49b and rabbit anti-NK1.1 Abs overnight at $4{ }^{\circ} \mathrm{C}$. After being rinsed with PBS, the sections were then incubated with a combination of Alexa Fluor 488 donkey anti-rat $\operatorname{IgG}$ $(1 / 100)$ and Alexa Fluor 594 goat anti-rabbit $\operatorname{IgG}(1 / 100)$ for $60 \mathrm{~min}$ at room temperature in the dark. Finally, the sections were washed with PBS and mounted with VECTASHIELD Mounting medium with DAPI, and immunofluorescence was visualized with a fluorescence microscope (Olympus, Tokyo, Japan). Images were processed by using graphics software (Adobe Photoshop, version7.0; Adobe, Mountain View, CA).

\section{Corneal whole mounts and morphological determination of neovascularization}

The excised corneas from the CrNV assay were rinsed in PBS and fixed in acetone for $20 \mathrm{~min}$. After washing and blocking with $2 \%$ bovine serum albumin (BSA) in PBS for $1 \mathrm{~h}$, corneas were stained overnight at $4{ }^{\circ} \mathrm{C}$ with a rat antimouse CD31 antibody (BD PharMingen). On day 2, CD31 was detected with an Alexa Fluor488-conjugated secondary donkey anti-rat antibody (Invitrogen). Corneas were moved to slides, covered with fluorescent mounting medium
(DAKO) and stored at $4{ }^{\circ} \mathrm{C}$ in the dark. Stained whole mounts were analyzed with a fluorescence microscope (MZ16; Leica, Wetzlar, Germany). Each whole mount picture was taken at $\times 25$ magnification. The area covered with neovascular tubes were determined with Image $\mathbf{J}$ software (available at http://rsb.info.nih.gov/ij/index.html), version 1.62 (National Institutes of Health, Bethesda, MD). The mean vascularized area of the control whole mounts was defined as being $100 \%$, vascularized areas were then related to this value (vessel ratio).

\section{RNA isolation and real-time PCR}

Total RNAs were extracted from the corneas using an RNeasy Mini Kit (Qiagen). The resultant RNA preparations were further treated with ribonuclease-free deoxyribonuclease (DNase) I (Life Technologies, Gaithersburg, MD, USA) to remove genomic DNA. The PCR solution contained $2 \mu \mathrm{l} \mathrm{cDNA}$, the specific primer set $(0.2 \mu \mathrm{M}$ final concentration), and $12.5 \mu \mathrm{l}$ of SYBR Premix Ex Taq in a final volume of $25 \mu \mathrm{l}$. The sequences of the PCR primer pairs are listed in Supplementary Table 1 (supplemental data 2). Quantitative PCR was performed using an iCycler iQ Multi-Color Real-Time PCR Detection System (BioRad, Hercules, CA, USA). The PCR parameters involved initial denaturation at $95^{\circ} \mathrm{C}$ for $1 \mathrm{~min}$, followed by 40 cycles of $95{ }^{\circ} \mathrm{C}$ for $5 \mathrm{~s}$ and $60^{\circ} \mathrm{C}$ for $30 \mathrm{~s}$. The relative gene expression levels were calculated using the $2^{-\Delta \Delta \mathrm{Ct}}$ method, where $\mathrm{Ct}$ represents the threshold cycle, and GAPDH was used as a reference gene.

\section{Western Blot}

Total ERK1/ERK2 and pERK1/ERK2 protein expression levels in WT mouse and BCL-10 mouse corneas were evaluated by western blot. The eyes were enucleated, and the corneal samples and other cell samples were placed in a $150 \mathrm{ml}$ lysis buffer $(20 \mathrm{mM}$ imidazole $\mathrm{HCl}, 10 \mathrm{mM} \mathrm{KCl}$, $1 \mathrm{mM} \mathrm{MgCl} 2,10 \mathrm{mM}$ EGTA, $1 \%$ Triton, $10 \mathrm{mM} \mathrm{NaF}, 1$ $\mathrm{mM}$ sodium molybdate, $1 \mathrm{mM}$ EDTA, $\mathrm{pH}$ 6.8), supplemented with a protease inhibitor cocktail (Boehringer Mannheim, Indianapolis, IN) and were sonicated. The lysate was centrifuged at $12,000 \mathrm{rpm}$ for $15 \mathrm{~min}$ at $4{ }^{\circ} \mathrm{C}$. Samples $(20 \mu \mathrm{g} / \mathrm{each}$ lane) were boiled for $5 \mathrm{~min}$ and separated by SDS-polyacrylamide gel electrophoresis under denaturing conditions and electroblotted to a polyvinylidene difluoride membrane (Bio-Rad, Hercules, CA). The membranes were blocked with $\mathrm{PBS} / 5 \%$ non-fat dry milk for nonspecific binding and incubated with antibodies as follows: anti-ERK1/ERK2 (BD PharMingen, San Diego, CA), anti-pERK1/ERK2 (BD PharMingen, San Diego, CA). Immunoblot assays were then washed and incubated with a horseradish peroxidase-labeled secondary 


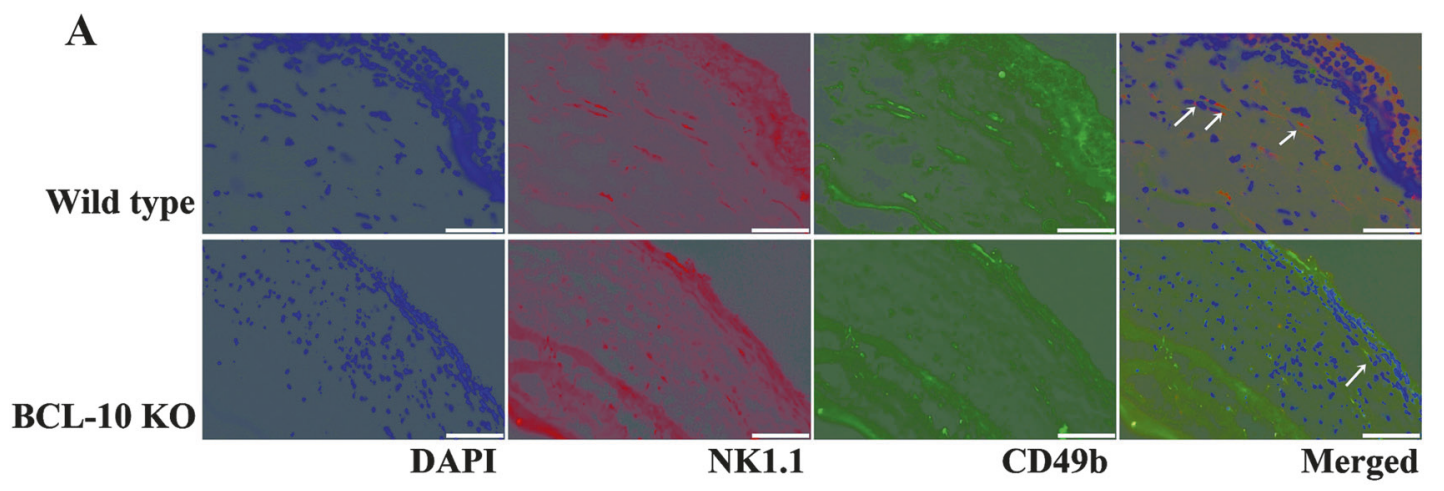

B

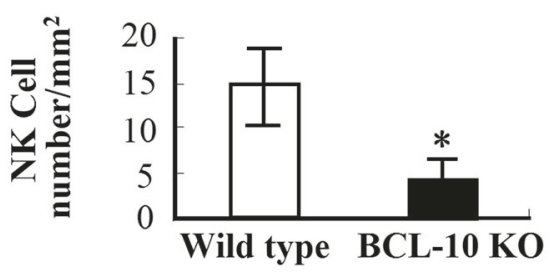

Fig. 1 A double-color immunofluorescence analysis of CD49b- and NK1.1-positive NK cells in the injured corneas of wild-type and BCL$10 \mathrm{KO}$ mice. Representative results from three independent

$\mathrm{Ab}$ (Amersham Pharmacia, Piscataway, NJ). The blot was visualized with enhanced chemiluminescence (ECL Plus; Amersham Pharmacia) according to the manufacturer's instructions.

\section{Flow cytometrical analysis of intracorneal macrophages, neutrophils, fibroblasts, epithelial cells and dendritic cells}

Mononuclear cells were isolated from corneas according to the procedure described previously with some modifications [25]. Briefly, at day 4 after the alkali injury, corneas were removed, teased away with scissors, and were incubated at $37^{\circ} \mathrm{C}$ for $30 \mathrm{~min}$ with constant shaking in the presence of $0.5 \mathrm{mg} / \mathrm{ml}$ collagenase type D (Roche Diagnostics, Mannheim, Germany). Cell suspensions were then passed over a nylon filter with $100 \mu \mathrm{m}$ pore size. The resultant cells were stained with rat anti-mouse F4/80, rat anti-mouse-Ly-6G, goat anti-Vimentin, FITCconjugated anti-mouse KRT, FITC-conjugated rat antimouse CD83, rabbit anti-mouse VEGF-A, rabbit antimouse bFGF, followed by staining with FITC-conjugated swine anti-rat IgG, or FITC-conjugated donkey anti-goat $\mathrm{IgG}$ and PE-conjugated donkey anti-rabbit IgG $\mathrm{mAb}$. Together with the samples stained with non-immunized rat $\mathrm{IgG}$, goat $\operatorname{IgG}$ or rabbit $\operatorname{IgG} \mathrm{mAb}$ as isotype controls, respectively.

In addition, in order to further examine the polarization of activated intracorneal macrophages after alkali injury in WT and BCL-10 KO mice, cells from the cornea samples experiments using immunofluorescence analysis. Original magnification, $\times 400$. Scale bar, $100 \mu \mathrm{m}$

were double stained with rat anti-mouse F4/80 and hamster anti-mouse CD11c for identification of M1 macrophages or rat anti-mouse F4/80 and goat anti-mouse CD206 for identification of M2 macrophages [26], followed by staining with PE-conjugated swine anti-rat IgG $\mathrm{mAb}$ or FITCconjugated donkey anti-goat $\operatorname{IgG} \mathrm{mAb}$. The samples stained with non-immunized rat IgG $\mathrm{mAb}$ or goat $\operatorname{IgG} \mathrm{mAb}$ were used as an isotype control. Data were acquired using a BD FACS Aria and were analyzed with FlowJo software (Tree Star, Ashland, OR).

\section{Statistical analysis}

All statistical analysis was performed on the SPSS 18.0 software (SPSS, Chicago, IL, USA). The means and SEM were calculated for all parameters determined in the study. Sample sizes were determined on the basis of similarly conducted studies [21-25]. Data were analyzed statistically using one-way analysis of variance, or two-tailed Student's $t$-test where appropriate. For $t$-test, equal variances between the groups were checked. A value of $P<0.05$ was considered statistically significant.

\section{Results}

\section{NK cell infiltration in the injured corneas}

It has been reported that BCL-10 is necessary for NK cell proliferation and activation [27]. Therefore, $B C L-10$ gene 
A

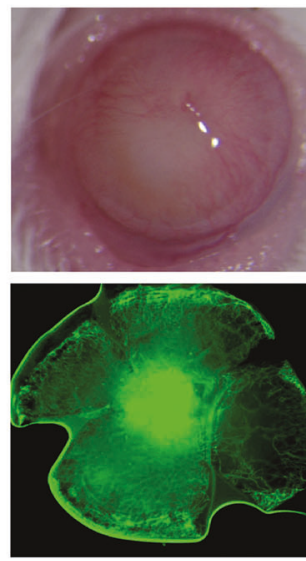

Wild type

B
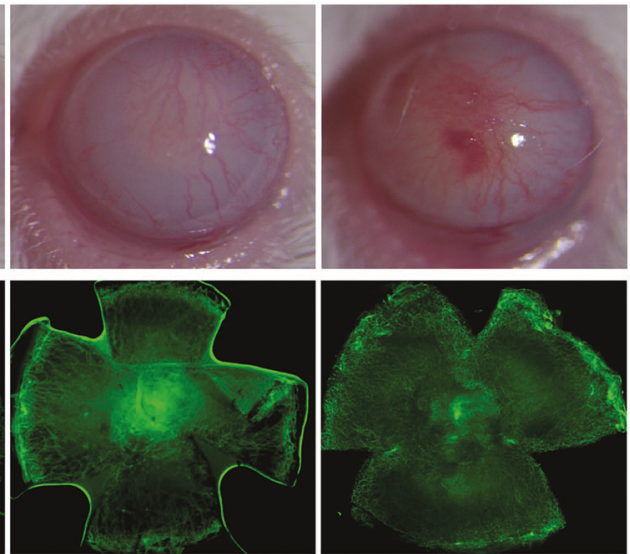

BCL-10 KO

BCL-10 KO

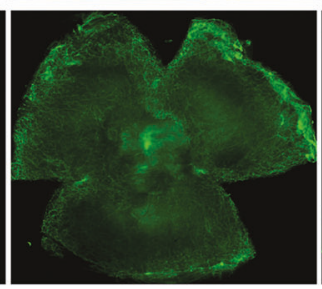

BCL-10 KO BCL-10 protein

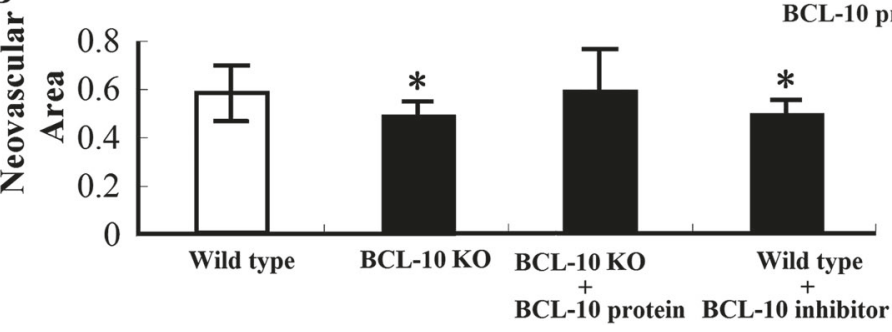

Fig. 2 The effects of BCL-10 on Alkali injury-induced CrNV. a Macroscopic appearance of mouse eyes and microscopic appearance of whole-corneal flat mounts of wild-type mouse, BCL-10 KO mouse, BCL-10 treated and anti-mouse BCL-10 antibody treated mouse eyes 2 weeks after alkali injury. Whole-corneal tissues were immunostained with anti-CD31 antibody and detected with an Alexa Fluor488conjugated secondary donkey anti-rat antibody, Images show representative whole-corneal flat mounts. CD31-vessels in the entire cornea were traced manually and were expressed as total pixels. Original magnifications, $\times 25$. b Proportions of $\mathrm{CrNV}$ areas of whole cornea tissue were determined from the corneas obtained from wildtype, BCL-10 KO, BCL-10 treated and anti-mouse BCL-10 antibody treated mice 2 weeks after injury. Each value represents mean \pm SEM ( $n=5-8$ animals). $* P<0.05$ compared with wild-type mice
KO may affect NK cell number and biological function. Thus, in the present study, we first examined NK cell infiltration in the injured corneas of WT and BCL-10 KO mice. We observed that CD49b/NK1.1-positive NK cells infiltrated in the injured corneas in WT mice. However, compared to WT mice $\left(15.1 \pm 4.4 / \mathrm{mm}^{2}\right)$, the number of NK cells infiltrating in the injured corneas was reduced $(4.4 \pm$ $\left.2.7 / \mathrm{mm}^{2}\right)$ in BCL-10 KO mice $(P<0.05$, Fig. 1). These observations indicated that $B C L-10$ gene $\mathrm{KO}$ markedly inhibited NK cell proliferation and migration.

\section{Effects of BCL-10 on alkali injury-induced CrNV}

Macroscopic examination demonstrated that alkali injury effectively increased the vascular areas in corneas to a greater extent in WT mice than in BCL-10 KO mice (Original magnifications, $\times 25)$. Corneal whole mount staining using anti-CD31 antibodies further revealed that the CD31positive areas in BCL-10 KO mice $(59 \pm 8.4 \%)$ were fewer compared with WT mice $(51 \pm 5.8 \%, P=0.048$; Fig. 2). However, when topically administrated with BCL-10 protein to the alkali-injured corneas of BCL-10 KO mice, the depression effect on CrNV was abrogated. These observations indicated that BCL-10 is involved in alkali-induced CrNV (Fig. 2).

\section{Reduced angiogenic factor expression in BCL-10 KO mice after alkali injury}

Angiogenic factors are necessary for neovascularization in various situations. Hence, the mRNA expression of the angiogenic factors, VEGF-A, bFGF and monocyte chemotactic protein 1 (MCP-1), in corneas after alkali injury was determined. The mRNA expression of VEGF$\mathrm{A}, \mathrm{bFGF}$ and MCP-1 was less augmented in BCL-10 KO mice (VEGF-A: $0.76 \pm 0.19$, bFGF: $0.81 \pm 0.11$, MCP-1: $0.71 \pm 0.14$ ) than in WT mice (VEGF-A: $1.00 \pm 0.05$, $P=0.042$; bFGF: $1.00 \pm 0.05, P=0.047$; MCP-1: $1.00 \pm$ $0.05, P=0.045)$ in the early phase after alkali injury (Fig. 3a). These observations indicated that BCL-10 regulated the increased expression of VEGF-A, bFGF, and MCP-1. When BCL-10 was depleted, the increased expression of angiogenic factors was inhibited and angiogenesis was then suppressed. 
A
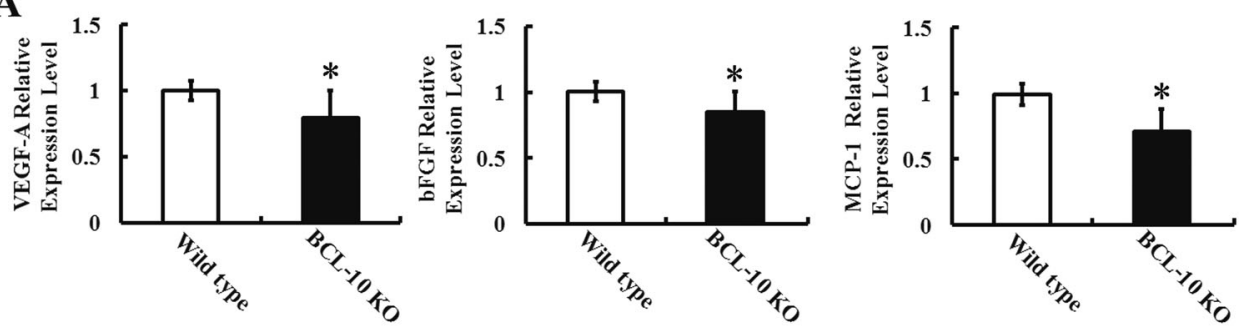

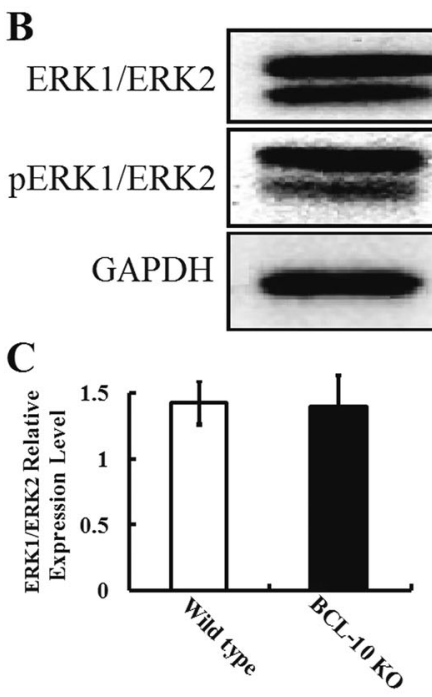

Fig. 3 Real-time PCR analysis of angiogenic gene expression and western blot analysis of protein expression of total ERK1/ERK2 and phosphorylated ERK1/ERK2 in the injured corneas of wild-type mice and BCL-10 KO mice. a Ratios of VEGF-A, bFGF and MCP-1 to GAPDH of alkali-injured wild-type mice (open bars), BCL-10 KO mice (black bars) were determined by real-time PCR at the indicated time intervals after alkali injury. Each value represents mean \pm SEM ( $n=5-8$ animals). $* P<0.05$ compared with wild-type mice versus

MAPK activation promotes endothelial migration, proliferation as an integral component of the VEGF signaling pathway. To determine whether BCL-10 affects cell migration and proliferation through the activation of MAPK, intracorneal total ERK1/ERK2 and pERK1/ERK2 expression were examined. pERK1/ERK2 expression was markedly reduced in BCL-10 KO mice compared with WT mice (Fig. 3b, c). These results suggest that BCL-10 induces ERK1/ERK2 phosphorylation via VEGF expression, and the detection of pERK1/ERK2 confirmed that MAPK activation in cells was dependent on VEGF expression, which was attributed to BCL-10 regulation (Fig. 3b, c).

\section{Decreased macrophage infiltration in the injured corneas in BCL-10 KO mice}

We previously observed that F4/80-positive macrophages infiltrated into the corneas following an alkali burn, and reached a peak level two to four days after injury in WT
BCL-10 KO mice. b Representative results determined by western blot from three independent experiments are shown here. $\mathbf{c}$ Ratios of total ERK1/ERK2 and pERK1/ ERK2 to GAPDH protein bands of wildtype mice (open bars) and BCL-10 KO mice (black bars) were determined as described in the Methods section. All values represent mean \pm SEM ( $n=5-8$ animals). $* P<0.05$ compared with wild-type mice

mice [25]. In the present study, we found that F4/80-positive cell infiltration into the corneas of BCL-10 KO mice $(4.2 \% \pm 0.4 \%)$ was less than that in WT mice $(6.3 \% \pm$ $0.5 \% ; P=0.045$; Fig. 4). These observations indicated that BCL-10 influenced the macrophage infiltration into the corneas.

According to previous reports [28, 29], macrophages can be activated and polarize into two types of M1 macrophages and M2 macrophages. In order to examine how BCL-10 is involved in $\mathrm{CrNV}$ by impacting on intracorneal macrophage infiltration and activation, the types of intracorneal macrophages were examined using FCM. There were approximately $35.5 \pm 2.4(\%)$ M1 macrophages and nearly $3.5 \pm 0.5$ (\%) M2 macrophages in the alkali injury corneas of WT mice, while in BCL-10 KO mice, the proportion of M1 macrophages was decreased to nearly $27.5 \pm 3.2(\%)$. There was no statistical difference in the proportion of intracorneal M2 macrophages between WT mice and BCL-10 KO mice. This suggested that BCL-10 mainly promoted M1 
Fig. 4 F4/80-positive cell numbers in corneas after alkali injury. Corneal tissues were obtained 4 days after injury from wild-type mice or BCL-10 KO mice and the tissues from 7 to 8 mice were combined and were subjected to analysis using a flow cytometer after being immunostained with anti-mouse F4/80 antibody. Isotype IgG derived from the same species of the test antibody was used as negative control. Representative results from three to four tests of intracorneal infiltration of F4/80 positive cells from either wildtype mice or BCL-10 KO mice are shown. ${ }^{*} P<0.05$ compared with wild-type mice versus BCL-10 KO mice

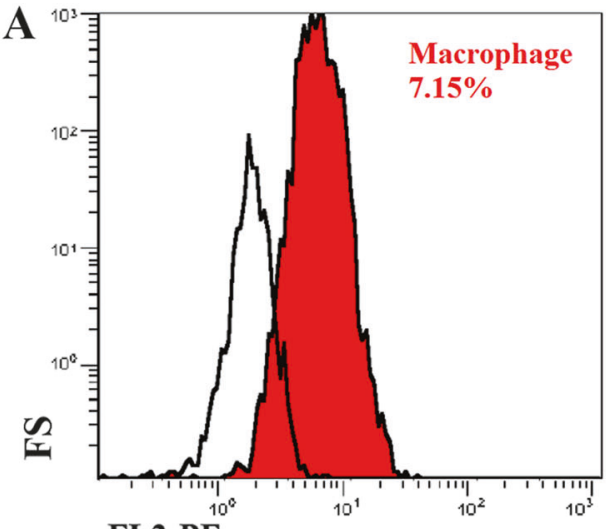

FL2-PE
Wild type

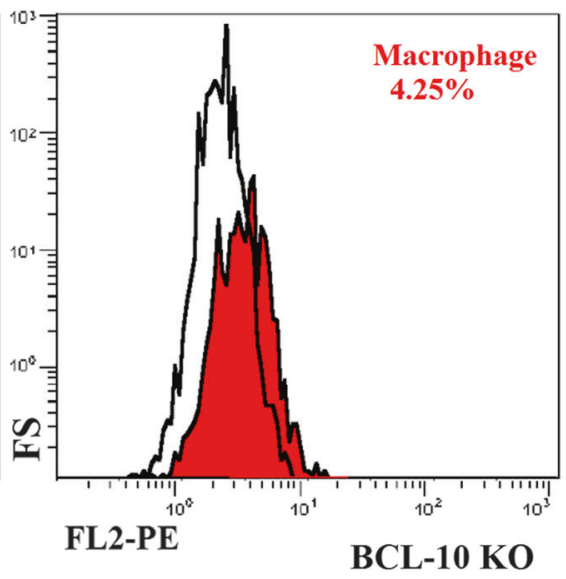

B

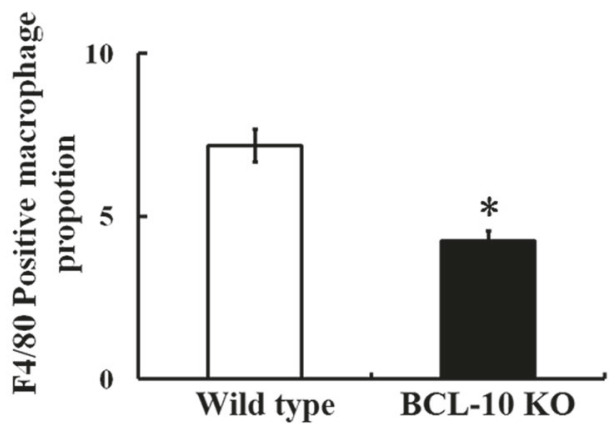

macrophage activation and infiltration into the alkali-injured corneas (Fig. 5).

\section{VEGF-A and bFGF expression in intracorneal macrophages, neutrophils, fibroblasts, dendritic cells and epithelial cells after alkali injury}

Given the fact that macrophages, neutrophils, fibroblasts, dendritic cells and epithelial cells are the important cells for secretion of VEGF and bFGF [30-32], we next examined the effects of BCL-10 on VEGF and bFGF secretion or expression of the intracorneal macrophages, neutrophils, fibroblasts, dendritic cells and epithelial cells. F4/80-positive macrophages accumulated to a lower extent in the corneas of BCL-10 KO mice than WT mice after the injury. Consistently, the number of VEGF-positive and bFGF-positive macrophages was markedly depressed in BCL-10 mice compared with WT mice (Fig. 5). Thus, BCL-10 may have an important role on regulating VEGF and bFGF secretion of F4/80-positive macrophages. However, there was no statistical significance in the number of VEGF-positive and bFGF-positive neutrophils, fibroblasts, dendritic cells and epithelial cells in the alkali injury corneas between BCL-10 KO mice and WT mice, suggesting that BCL-10 has no significant effects on VEGF and bFGF expression of neutrophils, fibroblasts, dendritic cells and epithelial cells (supplemental data 1).

\section{Discussion}

BCL-10 has been identified as a novel signal which activates NF-кB, JNK, and p38 upon activation of NK-cell receptor triggering and segregates the signals for cytokine production from NK-cell proliferation and killing [27]. Gross et al. [13] found that BCL-10 is not only required for the activation of NK cells via agonistic antibodies directed against specific activation of NK-cell receptors, but also for direct NK-cell activation via PMA/Iono signal. Moreover, cytokines, which produced by NK cell, are also regulated by the BCL-10 signal [33]. Although poor long-term cytokine producers, NK cells have recently been shown to rapidly $(2-4 \mathrm{~h})$ release substantial levels of cytokines [34]. It is possible that the secretion of cytokines, such as IFN- $\gamma$, TNF- $\alpha$, and GM-CSF to resist viral infections, and VEGF$\mathrm{A}, \mathrm{bFGF}$, and PIGF to promote angiogenesis, may be impaired in the absence of BCL-10 signaling in NK cells [35].

Several studies have shown that NK cells are linked to angiogenesis during tissue repair. Mice deficient in NK cells showed defective myocardial repair, and gene expression profiling and immunohistochemistry indicated a role for NK cells [36]. Furthermore, NK cells in non-small cell lung carcinoma patients with squamous cell carcinoma produced substantially higher levels of VEGF-A and PIGF compared to those with adenocarcinomas [37]. 
Fig. 5 FCM analysis of M1 and M2 macrophage infiltration in normal and alkali-injured corneas. a Representative results from three to four tests of intracorneal infiltration of $\mathrm{F} 4 / 80$ / CD11c- or F4/80/CD206positive cells from wild-type mice and BCL-10 KO mice are shown. b, c Representative results from three to four tests of intracorneal infiltration of F4/80/ VEGF-A- or F4/80/bFGFpositive cells from wild-type mice and BCL-10 KO mice are shown. d Proportion of M1 and M2 macrophages. e, f Ratios of VEGF-A and bFGF on F4/80positive macrophages in alkaliinjured wild-type mice (open bars) and BCL-10 KO mice (black bars) using FCM. All values represent mean \pm SEM ( $n=6-8$ animals). $* P<0.05$ compared with wild-type mice
A

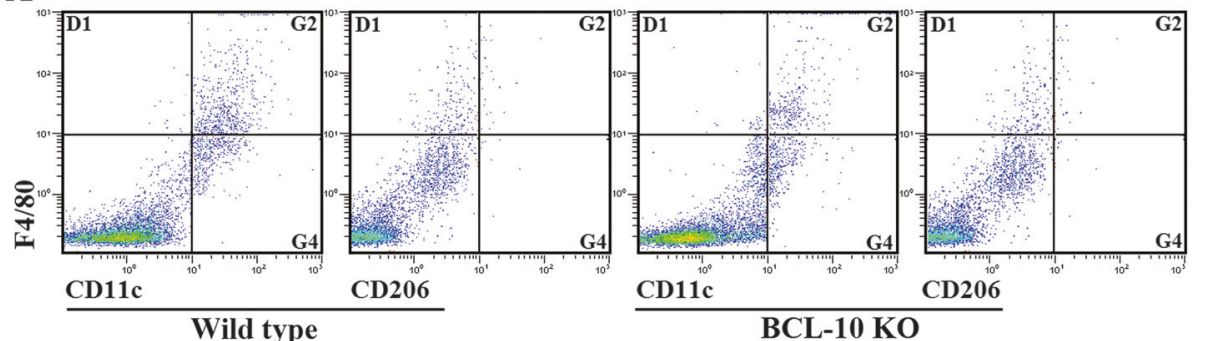

B

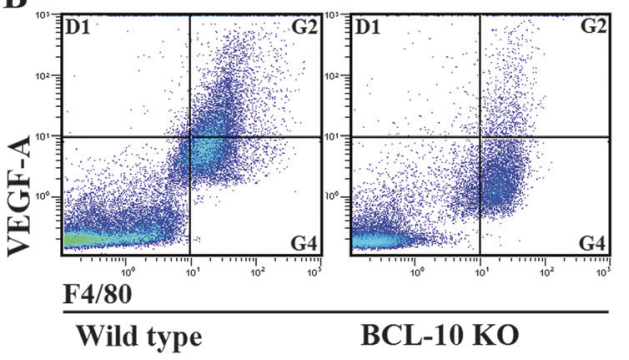

C

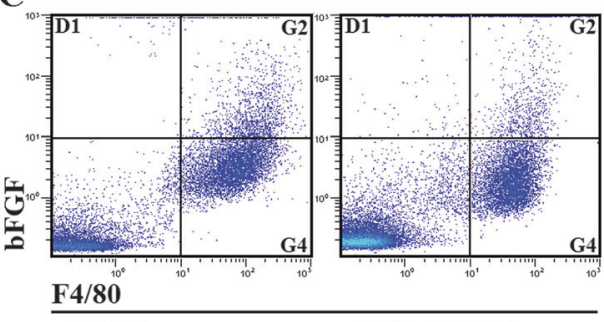

Wild type

BCL-10 KO

F

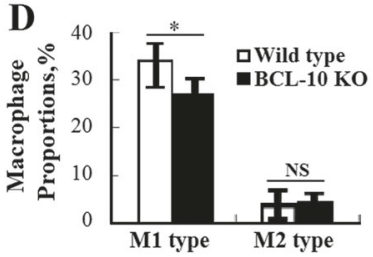

$\mathbf{E}$
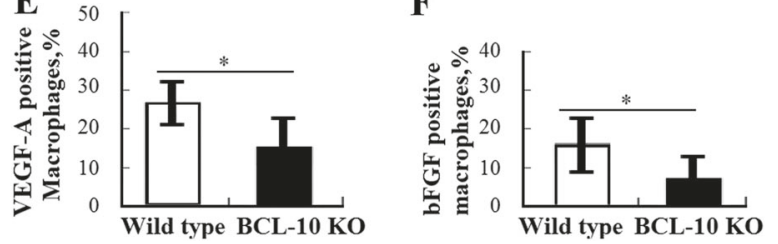

Therefore, we hypothesized that NK cell activation and proliferation regulated by BCL-10 signaling have a role in CrNV. Thus, we investigated the role of BCL-10 in experimental $\mathrm{CrNV}$ using BCL-10 KO and WT mice. Here we demonstrate that BCL-10 KO leads to decreased CrNV in vivo. The effect of BCL-10 on CrNV was associated with reduced intracorneal $V E G F-A, b F G F$, and $M C P-1$ mRNA expression.

The process of angiogenesis is associated with the balance between proangiogenic and antiangiogenic molecule expressions under physiologic conditions. However, when this balance is disrupted, neovascularization may occur under pathological conditions [38]. To the best of our knowledge, angiogenic factors, such as VEGF-A and bFGF play pivotal roles in stimulating blood vessel formation [39]. These factors are secreted by various cells, including macrophages and neutrophils [40]. VEGF-A is the most widely studied ligand of the VEGF family, and it plays an important role in the formation of $\mathrm{CNV}$ by several mechanisms [41, 42], including the release of matrix metalloproteinases [43], endothelial cell survival [44], CEC migration and proliferation [45-47], and increased permeability [48, 49]. Of note, the family of VEGF-related molecules contains other members, such as VEGF-B, VEGF-C, and VEGF-D [50]. VEGF-B is prominently expressed in the cardiac myocytes, in skeletal muscle and smooth muscle cells of large vessels [51, 52]. VEGF-C expression is prominent in the mesenchyme, around the developing metanephrons and in the jugular area, in regions where the lymphatic vessels are developing in association with venous sac-like structures [53]. VEGF-B, VEGF-C, and VEGF-D, unlike VEGF-A, are potent inducers of lymph angiogenesis [54]. In the present study, we mainly determined the mRNA expression of $V E G F-A, b F G F$, and $M C P-1$ in mouse corneas after alkali injury. We found that the expression of VEGF-A, bFGF, and $M C P-1$ in the corneas of BCL-10 KO mice was significantly downregulated. These findings indicated that BCL-10 may be involved in the process of $\mathrm{CrNV}$ by skewing the balance toward the proangiogenic state, and subsequently enhancing $\mathrm{CrNV}[55$, 56].

Several lines of evidence indicate that macrophages can be proangiogenic by producing angiogenic factors in ocular neovascularization [57-61]. Lee $\mathrm{H}$ et al. reported that NK cells had the ability to recruit macrophages to lesion sites by the secretion of a serious of chemokines [62]. In our study, we also examined the intracorneal $M C P-1$ mRNA expression in BCL-10 KO and WT mice. Interestingly, our real-time PCR results indicated that the intracorneal mRNA expression of $M C P-1$ was decreased in BCL-10 KO mice. MCP-1 is a critical chemokine and has the ability to recruit macrophages into pathological tissues. 
Hence, we hypothesized that BCL-10 signaling may affect CrNV by inducing macrophage recruitment. Consistent with our hypothesis, we found that the level of intracorneal F4/80-positive macrophage/monocyte infiltration in BCL$10 \mathrm{KO}$ mice was less than that in WT mice. This suggested that BCL-10 signaling has a role in experimental CrNV, partly by influencing the intracorneal macrophage infiltration.

Some studies showed that macrophages can be activated and polarize into several different types, such as dividing into M1 and M2 [63, 64]. M1 macrophages are proinflammatory cells, while M2 macrophages are antiinflammatory cells. In order to precisely elucidate the BCL-10 effects on intracorneal macrophage migration and activation, CD11c positive M1 and CD206-positive M2 macrophage infiltration was also evaluated using FCM. We found that, in BCL-10 KO mice, the number of intracorneal M1 macrophages was significantly reduced, while the number of M2 macrophages was not changed, indicating that BCL-10 enhances inflammatory factors secretion may through promoting pro-inflammatory cells, such as M1 macrophages, migration into lesions. These findings suggest that BCL-10 has the ability to facilitate M1 macrophage migration and activation and promote macrophage secretion of angiogenic cytokines, such as VEGF and bFGF and subsequently enhances experimental corneal neovascularization.

Several lines of evidence indicate that neutrophils, fibroblasts, dendritic cells and epithelial cells as well as macrophages form prominent parts of inflammatory response and have important roles on angiogenesis. These cells contribute to the extent of $\mathrm{CNV}$ by acting as an additional source of VEGF-A and bFGF [30-32]. In order to determine whether BCL-10 has effect on $\mathrm{CrNV}$ through influencing VEGF and bFGF expression of above cells, we also detected and compared VEGF-A and bFGF expression in intracorneal neutrophils, fibroblasts, dendritic cells and epithelial cells between WT mice and BCL-10 KO mice. Actually, there was no statistical significance on the number of intracorneal VEGF-A-positive and bFGF-positive neutrophils, fibroblasts, dendritic cells and epithelial cells between WT and BCL-10 KO mice. These experiments indicated that BCL-10 influenced the CrNV development by macrophages rather than by neutrophils, fibroblasts, dendritic cells or epithelial cells.

The ERK signaling cascade is a central MAPK pathway that plays a role in the regulation of various cellular processes such as proliferation, differentiation, development, learning and survival [65]. Activation of MAP kinase is a known VEGF-A downstream signaling event [66]. Several lines of evidence indicate that the pathway is involved in the process of neovascularization $[67,68]$. Thus, in our present study, we also analyzed the effect of BCL-10 on the phosphorylation of MAP kinases, ERK1 (p44) and ERK2 (p42) by western blot analysis. We found that BCL-10 could stimulate the phosphorylation of intracorneal ERK1/ ERK2 after alkali injury. The results indicate that BCL-10 can promote CrNV through facilitating phosphorylation of ERK1/ERK2.

In our present study, we found that BCL-10 is involved in the process of neovascularization in experimental alkaliinduced CrNV model. Our results suggest that BCL-10 signaling enhances CrNV. Furthermore, VEGF-A and $\mathrm{bFGF}$, the most important proangiogenic factors in angiogenesis, were reduced in BCL-10 KO mice compared to WT mice. Furthermore, the level of intracorneal macrophages infiltration was less in BCL-10 KO mice than in WT mice. Taken together, these findings suggest that BCL-10 can promote $\mathrm{CrNV}$ by activating NK cells and inducing the proliferation of NK cells. Since NK cell activation and proliferation was deteriorated in BCL-10 $\mathrm{KO}$ mice, proangiogenesis efficacy via induction of VEGF-A and bFGF secretion and the promotion of macrophage infiltration was subsequently depressed.

The BCL-10 KO mice exhibit remarkably attenuated alkali-induced $\mathrm{CrNV}$, indicating the crucial involvement of BCL-10 in neovascularization. Corneal neovascularization is one of the leading causes of blindness worldwide. Gross and colleagues reported that BCL-10 is capable of promoting NK cell activation and thereby promoting NK cells proangiogenic factors secretion [13]. Bruno et al. observed that NK cells have been shown to possess proangiogenic property in non-small cell lung cancer [37], to remodel maternal vasculature in early pregnancy [69], and to induce angiogenesis by promoting enhanced VEGF expression by macrophages in the cornea micro pocket assays [62]. Considered that the BCL-10 signaling can regulate proangiogenic activities of NK cells, it is tempting to conclude that the signaling has a crucial role in CrNV. In this respect, blockade of BCL-10 may be effective for clinical treatment and/or prevention of CrNV. Further studies of the physiological regulation of BCL-10 may thus be useful for future treatments for persistent $\mathrm{CrNV}$ that are found in clinical settings.

\section{Summary}

\section{What was known before}

- Corneal Neovascularization, B-cell leukemia/lymphoma 10

\section{What this study adds}

- The effects and mechanism of B-cell leukemia/lymphoma 10 on Corneal Neovascularization 
Acknowledgements We thank D. Liu Haiyan for sharing the BCL-10 KO mice. This research was supported by the National Natural Science Foundation in China (NSFC No 81200727, No 81671641), Suzhou Municipal Natural Science Foundation (No. SYS201745), Soochow University Doctoral Academic Talents Program (No. 5832001313), Jiangsu Provincial Medical Youth Talent (No. QNRC2016718), Jiangsu Provincial Medical Innovation Team (No. CXTDA2017039), Jiangsu Provincial Natural Science Foundation (No. BK20151208) and the Soochow Scholar Project of Soochow University (No. R5122001).

\section{Compliance with ethical standards}

Conflict of interest The authors declare that they have no conflict of interest.

Open Access This article is licensed under a Creative Commons Attribution-NonCommercial-NoDerivatives 4.0 International License, which permits any non-commercial use, sharing, distribution and reproduction in any medium or format, as long as you give appropriate credit to the original author(s) and the source, and provide a link to the Creative Commons license. You do not have permission under this license to share adapted material derived from this article or parts of it. The images or other third party material in this article are included in the article's Creative Commons license, unless indicated otherwise in a credit line to the material. If material is not included in the article's Creative Commons license and your intended use is not permitted by statutory regulation or exceeds the permitted use, you will need to obtain permission directly from the copyright holder. To view a copy of this license, visit http://creativecommons.org/licenses/by-nc-nd/4.0/.

\section{References}

1. Chang JH, Garg NK, Lunde E, Han KY, Jain S, Azar DT. Corneal neovascularization: an anti-VEGF therapy review. Surv Ophthalmol. 2012;57:415-29.

2. Manzano RP, Peyman GA, Khan P, Carvounis PE, Kivilcim M, Ren $\mathrm{M}$, et al. Inhibition of experimental corneal neovascularisation by bevacizumab (Avastin). Br J Ophthalmol. 2007;91:804-7.

3. Gao N, Liu X, Wu J, Li J, Dong C, Wu X, et al. CXCL10 suppression of hem- and lymph-angiogenesis in inflamed corneas through MMP13. Angiogenesis. 2017;20:505-18

4. Lee P, Wang CC, Adamis AP. Ocular neovascularization: an epidemiologic review. Surv Ophthalmol. 1998;43:245-69.

5. Chang JH, Gabison EE, Kato T, Azar DT. Corneal neovascularization. Curr Opin Ophthalmol. 2001;12:242-9.

6. Koenig Y, Bock F, Kruse FE, Stock K, Cursiefen C. Angioregressive pretreatment of mature corneal blood vessels before keratoplasty: fine-needle vessel coagulation combined with antiVEGFs. Cornea. 2012;31:887-92.

7. Shen L, Liang AC, Lu L, Au WY, Wong KY, Tin PC, et al. Aberrant BCL10 nuclear expression in nasal NK/T-cell lymphoma. Blood. 2003;102:1553-4.

8. Ferch U, zum Büschenfelde CM, Gewies A, Wegener E, Rauser $\mathrm{S}$, Peschel $\mathrm{C}$, et al. MALT1 directs B cell receptor-induced canonical nuclear factor-kappaB signaling selectively to the c-Rel subunit. Nat Immunol. 2007;8:984-91.

9. Ruefli-Brasse AA, French DM, Dixit VM. Regulation of NFkappaB-dependent lymphocyte activation and development by paracaspase. Science. 2003;302:1581-4.

10. Ruland J, Duncan GS, Elia A, del Barco Barrantes I, Nguyen L, et al. Bcl10 is a positive regulator of antigen receptor-induced activation of NF-kappaB and neural tube closure. Cell. 2001;104:33-42.

11. Ruland J, Duncan GS, Wakeham A, Mak TW. Differential requirement for Malt1 in $\mathrm{T}$ and $\mathrm{B}$ cell antigen receptor signaling. Immunity. 2003;19:749-58.

12. Xue L, Morris SW, Orihuela C, Tuomanen E, Cui X, Wen R, et al. Defective development and function of Bcl10-deficient follicular, marginal zone and B1 B cells. Nat Immunol. 2003;4:857-65.

13. Gross O, Grupp C, Steinberg C, Zimmermann S, Strasser D, Hannesschläger N, et al. Multiple ITAM-coupled NK-cell receptors engage the Bcl10/Malt1 complex via Carma1 for NF- $\mathrm{kB}$ and MAPK activation to selectively control cytokine production. Blood. 2008;112:2421-8.

14. Schmidt-Supprian M, Tian J, Grant EP, Pasparakis M, Maehr R, Ovaa $\mathrm{H}$, et al. Differential dependence of CD4+CD25+regulatory and natural killer-like $\mathrm{T}$ cells on signals leading to NF-kappaB activation. Proc Natl Acad Sci USA. 2004;101:4566-71.

15. Hanna J, Goldman-Wohl D, Hamani Y, Avraham I, Greenfield C, Natanson-Yaron S, et al. Decidual NK cells regulate key developmental processes at the human fetal-maternal interface. Nat Med. 2006;12:1065-74.

16. Santoni A, Carlino C, Stabile H, Gismondi A. Mechanisms underlying recruitment and accumulation of decidual NK cells in uterus during pregnancy. Am J Reprod Immunol. 2008;59:417-24.

17. Vacca P, Moretta L, Moretta A, Mingari MC. Origin, phenotype and function of human natural killer cells in pregnancy. Trends Immunol. 2011;32:517-23.

18. Vivier E, Ugolini S, Blaise D, Chabannon C, Brossay L. Targeting natural killer cells and natural killer $\mathrm{T}$ cells in cancer. Nat Rev Immunol. 2012;12:239-52.

19. Martin D, Galisteo R, Gutkind JS. CXCL8/IL8 stimulates vascular endothelial growth factor (VEGF) expression and the autocrine activation of VEGFR2 in endothelial cells by activating NFkap$\mathrm{paB}$ through the CBM (Carma3/Bcl10/Malt1) complex. J Biol Chem. 2009;284:6038-42.

20. Srivastava S, Lundqvist A, Childs RW. Natural killer cell immunotherapy for cancer: a new hope. Cytotherapy. 2008; 10:775-83.

21. Lu P, Li L, Kuno K, Wu Y, Baba T, Li YY, et al. Protective roles of the fractalkine/CX3CL1-CX3CR1 interactions in alkaliinduced corneal neovascularization through enhanced antiangiogenic factor expression. J Immunol. 2008;180:4283-91.

22. Lu P, Li L, Wu Y, Mukaida N, Zhang X. Essential contribution of CCL3 to alkali-induced corneal neovascularization by regulating vascular endothelial growth factor production by macrophages. Mol Vis. 2008;14:1614-22.

23. Lu P, Li L, Liu G, van Rooijen N, Mukaida N, Zhang X. Opposite roles of CCR2 and CX3CR1 macrophages in alkali-induced corneal neovascularization. Cornea. 2009;28:562-9.

24. Lu P, Li L, Liu G, Zhang X, Mukaida N. Enhanced experimental corneal neovascularization along with aberrant angiogenic factor expression in the absence of IL-1 receptor antagonist. Invest Ophthalmol Vis Sci. 2009;50:4761-8.

25. Liu G, Lu P, Li L, Jin H, He X, Mukaida N, et al. Critical role of SDF-1 $\alpha$-induced progenitor cell recruitment and macrophage VEGF production in the experimental corneal neovascularization. Mol Vis. 2011;17:2129-38.

26. Zhu Y, Tan W, Demetriades AM, Cai Y, Gao Y, Sui A, et al. Interleukin-17A neutralization alleviated ocular neovascularization by promoting M2 and mitigating M1 macrophage polarization. Immunology. 2016;147:414-28.

27. Rajasekaran K, Kumar P, Schuldt KM, Peterson EJ, Vanhaesebroeck B, Dixit V, et al. Signaling by Fyn-ADAP via the Carma1-Bcl-10-MAP3K7 signalosome exclusively regulates 
inflammatory cytokine production in NK cells. Nat Immunol. 2013;14:1127-36.

28. Fuchs AK, Syrovets T, Haas KA, Loos C, Musyanovych A, Mailänder $\mathrm{V}$, et al. Carboxyl- and amino-functionalized polystyrene nanoparticles differentially affect the polarization profile of M1 and M2 macrophage subsets. Biomaterials. 2016;85:78-87.

29. Liang W, Ferrara N. The complex role of neutrophils in tumor angiogenesis and metastasis. Cancer Immunol Res. 2016;4:83-91.

30. Liu G, Wu H, Lu P, Zhang X. Interleukin (IL)-17A promotes angiogenesis in an experimental corneal neovascularization model. Curr Eye Res. 2016;15:1-12.

31. Barrientos G, Tirado-González I, Freitag N, Kobelt P, Moschansky P, Klapp BF, et al. CXCR4(+) dendritic cells promote angiogenesis during embryo implantation in mice. Angiogenesis. 2013;16:417-27.

32. Wang Y, Sang A, Zhu M, Zhang G, Guan H, Ji M, et al. Tissue factor induces VEGF expression via activation of the $\mathrm{Wnt} / \beta$ catenin signaling pathway in ARPE-19 cells. Mol Vis. 2016;22:886-97.

33. Fauriat C, Long EO, Ljunggren HG, Bryceson YT. Regulation of human NK-cell cytokine and chemokine production by target cell recognition. Blood. 2010;115:2167-76.

34. De Maria A, Bozzano F, Cantoni C, Moretta L. Revisiting human natural killer cell subset function revealed cytolytic CD56(dim) $\mathrm{CD} 16+\mathrm{NK}$ cells as rapid producers of abundant IFN-gamma on activation. Proc Natl Acad Sci USA. 2011;108:728-32.

35. Ayach BB, Yoshimitsu M, Dawood F, Sun M, Arab S, Chen M, et al. Stem cell factor receptor induces progenitor and natural killer cell-mediated cardiac survival and repair after myocardial infarction. Proc Natl Acad Sci USA. 2006;103:2304-9.

36. Bouchentouf M, Forner KA, Cuerquis J, Michaud V, Zheng J, Paradis $\mathrm{P}$, et al. Induction of cardiac angiogenesis requires killer cell lectin-like receptor 1 and alpha4beta7 integrin expression by NK cells. J Immunol. 2010;185:7014-25.

37. Bruno A, Focaccetti C, Pagani A, Imperatori AS, Spagnoletti M, Rotolo N, et al. The proangiogenic phenotype of natural killer cells in patients with non-small cell lung cancer. Neoplasia. 2013;15:133-42.

38. Martínez A. A new family of angiogenic factors. Cancer Lett. 2006;236:157-63.

39. Uno K, Hayashi H, Kuroki M, Uchida H, Yamauchi Y, Kuroki M, et al. Thrombospondin-1 accelerates wound healing of corneal epithelia. Biochem Biophys Res Commun. 2004;315:928-34.

40. Sakaguchi I, Ikeda N, Nakayama M, Kato Y, Yano I, Kaneda K. Trehalose 6,6'-dimycolate (Cord factor) enhances neovascularization through vascular endothelial growth factor production by neutrophils and macrophages. Infect Immun. 2000;68:2043-52.

41. Klagsbrun M, D'Amore PA. Regulators of angiogenesis. Annu Rev Physiol. 1991;53:217-39.

42. Risau W. Mechanisms of angiogenesis. Nature. 1997;386:671-4.

43. Lamoreaux WJ, Fitzgerald ME, Reiner A, Hasty KA, Charles ST. Vascular endothelial growth factor increases release of gelatinase A and decreases release of tissue inhibitor of metalloproteinases by microvascular endothelial cells in vitro. Microvasc Res. 1998;55:29-42.

44. Vinci MC, Visentin B, Cusinato F, Nardelli GB, Trevisi L, Luciani S. Effect of vascular endothelial growth factor and epidermal growth factor on iatrogenic apoptosis in human endothelial cells. Biochem Pharmacol. 2004;67:277-84

45. Roeckl W, Hecht D, Sztajer H, Waltenberger J, Yayon A, Weich HA. Differential binding characteristics and cellular inhibition by soluble VEGF receptors 1 and 2. Exp Cell Res. 1998;241:161-70.

46. Zachary I, Gliki G. Signaling transduction mechanisms mediating biological actions of the vascular endothelial growth factor family. Cardiovasc Res. 2001;49:568-81.
47. Ishibashi $\mathrm{T}$, Hata $\mathrm{Y}$, Yoshikawa H, Nakagawa K, Sueishi K, Inomata $\mathrm{H}$. Expression of vascular endothelial growth factor in experimental choroidal neovascularization. Graefes Arch Clin Exp Ophthalmol. 1997;235:159-67.

48. Senger DR, Galli SJ, Dvorak AM, Perruzzi CA, Harvey VS, Dvorak HF. Tumor cells secrete a vascular permeability factor that promotes accumulation of ascites fluid. Science. 1983;219:983-5.

49. Ashton AW, Ware JA. Thromboxane A2 receptor signaling inhibits vascular endothelial growth factor-induced endothelial cell differentiation and migration. Circ Res. 2004;95:372-9.

50. Veikkola T, Alitalo K. VEGFs, receptors and angiogenesis. Semin Cancer Biol. 1999;9:211-20.

51. Olofsson B, Pajusola K, Kaipainen A, von Euler G, Joukov V, Saksela $\mathrm{O}$, et al. Vascular endothelial growth factor B, a novel growth factor for endothelial cells. Proc Natl Acad Sci USA. 1996;93:2576-81.

52. Aase K, Lymboussaki A, Kaipainen A, Olofsson B, Alitalo K, Eriksson U. Localization of VEGF-B in the mouse embryo suggests a paracrine role of the growth factor in the developing vasculature. Dev Dyn. 1999;215:12-25.

53. Kukk E, Lymboussaki A, Taira S, Kaipainen A, Jeltsch M, Joukov $\mathrm{V}$, et al. VEGF-C receptor binding and pattern of expression with VEGFR-3 suggests a role in lymphatic vascular development. Development. 1996;122:3829-37.

54. Olofsson B, Jeltsch M, Eriksson U, Alitalo K. Current biology of VEGF-B and VEGF-C. Curr Opin Biotechnol. 1999;10:528-35.

55. Edelman JL, Castro MR, Wen Y. Correlation of VEGF expression by leukocytes with the growth and regression of blood vessels in the rat cornea. Invest Ophthalmol Vis Sci. 1999;40:1112-23.

56. Lai CM, Spilsbury K, Brankov M, Zaknich T, Rakoczy PE. Inhibition of corneal neovascularization by recombinant adenovirus mediated antisense VEGF RNA. Exp Eye Res. 2002;75:625-34.

57. Sakurai E, Anand A, Ambati BK, van Rooijen N, Ambati J. Macrophage depletion inhibits experimental choroidal neovascularization. Invest Ophthalmol Vis Sci. 2003;44: 3578-85.

58. Grossniklaus HE, Ling JX, Wallace TM, Dithmar S, Lawson DH, Cohen $\mathrm{C}$, et al. Macrophage and retinal pigment epithelium expression of angiogenic cytokines in choroidal neovascularization. Mol Vis. 2002;8:119-26.

59. Tsutsumi C, Sonoda KH, Egashira K, Qiao H, Hisatomi T, Nakao $\mathrm{S}$, et al. The critical role of ocular-infiltrating macrophages in the development of choroidal neovascularization. J Leukoc Biol. 2003;74:25-32.

60. Espinosa-Heidmann DG, Suner IJ, Hernandez EP, Monroy D, Csaky KG, Cousins SW. Macrophage depletion diminishes lesion size and severity in experimental choroidal neovascularization. Invest Ophthalmol Vis Sci. 2003;44:3586-92.

61. Oh H, Takagi H, Takagi C, Suzuma K, Otani A, Ishida K, et al. The potential angiogenic role of macrophages in the formation of choroidal neovascular membranes. Invest Ophthalmol Vis Sci. 1999;40:1891-8.

62. Lee H, Schlereth SL, Park EY, Emami-Naeini P, Chauhan SK, Dana R. A novel pro-angiogenic function for interferon- $\gamma$ secreting natural killer cells. Invest Ophthalmol Vis Sci. 2014;55:2885-92.

63. Dufresne M, Dumas G, Asselin E, Carrier C, Pouliot M, ReyesMoreno C. Pro-inflammatory type-1 and anti-inflammatory type-2 macrophages differentially modulate cell survival and invasion of human bladder carcinoma T24 cells. Mol Immunol. 2011;48:1556-67.

64. Zhu Y, Li X, Chen J, Chen T, Shi Z, Lei M, et al. The pentacyclic triterpene Lupeol switches M1 macrophages to M2 and 
ameliorates experimental inflammatory bowel disease. Int Immunopharmacol. 2016;30:74-84.

65. Shaul YD, Seger R. The MEK/ERK cascade: from signaling specificity to diverse functions. Biochim Biophys Acta. 2007;1773:1213-26.

66. Qi JH, Ebrahem Q, Ali M, Cutler A, Bell B, Prayson N, et al. Tissue inhibitor of metalloproteinases-3 peptides inhibit angiogenesis and choroidal neovascularization in mice. PLoS ONE. 2013;8:e55667.

67. Liao WX, Feng L, Zhang H, Zheng J, Moore TR, Chen DB. Compartmentalizing VEGF-induced ERK2/1 signaling in placental artery endothelial cell caveolae: a paradoxical role of caveolin-1 in placental angiogenesis in vitro. Mol Endocrinol. 2009;23:1428-44.

68. Akhand AA, Hossain K, Mitsui H, Kato M, Miyata T, Inagi R, et al. Glyoxal and methylglyoxal trigger distinct signals for map family kinases and caspase activation in human endothelial cells. Free Radic Biol Med. 2001;31:20-30.

69. Rajagopalan S, Long EO. Cellular senescence induced by CD158d reprograms natural killer cells to promote vascular remodeling. Proc Natl Acad Sci USA. 2012;109:20596-601. 